\title{
An Unusual Cause of Hypoglycaemia
}

\author{
S Law, T O'Shea, P Hyatt, A Garg, C Nethaji
}

Department of Endocrinology and Diabetes Mellitus, North Middlesex University Hospital

\section{INTRODUCTION}

Hypoglycaemia is a common presentation to Emergency Care, but is most commonly associated with treatment for diabetes mellitus. We discuss a case of severe recurrent hypoglycaemia in an elderly patient with several comorbidities.

\section{PRESENTATION}

An 84 year old female presented to the Emergency Department following an episode of collapse at home. She had a known background history of Stage IV chronic kidney disease and a longstanding benign tumour situated in the lower lobe of her left lung. She reported a history of recurrent collapses over the preceding two years, associated with discrete periods of sweating and confusion. She also reported an increase in appetite and significant weight gain over this time period. Capillary blood glucose in the Emergency Department was $2.6 \mathrm{mmol} / \mathrm{L}$; venous blood glucose $2.8 \mathrm{mmol} / \mathrm{L}$. She was admitted for further investigation and management.

\section{INVESTIGATIONS}

She suffered recurrent episodes of hypoglycaemia on the ward.

\section{Biochemical Investigations}

-Capillary Blood glucose: $2.5 \mathrm{mmol} / \mathrm{L}$

-Venous Blood glucose: $3.2 \mathrm{mmol} / \mathrm{L}$

-Cortisol: 413nmol/L

-Insulin: $<1.0 \mathrm{mU} / \mathrm{L}$

-C-Peptide: 122pmol/L (<200pmol/L in hypoglycaemia)

-IGF1: $4.2 \mathrm{nmol} / \mathrm{L}$

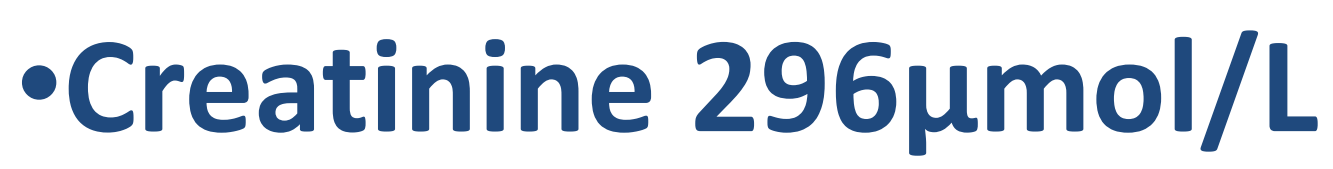

Given her presentation and her biochemical investigations and imaging non-islet cell tumour hypoglycaemia was suspected and IGF2 levels were measured.

-IGF2: 236.4nmol/L

-IGF2:IGF1 31.1

Thus a diagnosis of non-islet cell tumour hypoglycaemia was made.
Imaging
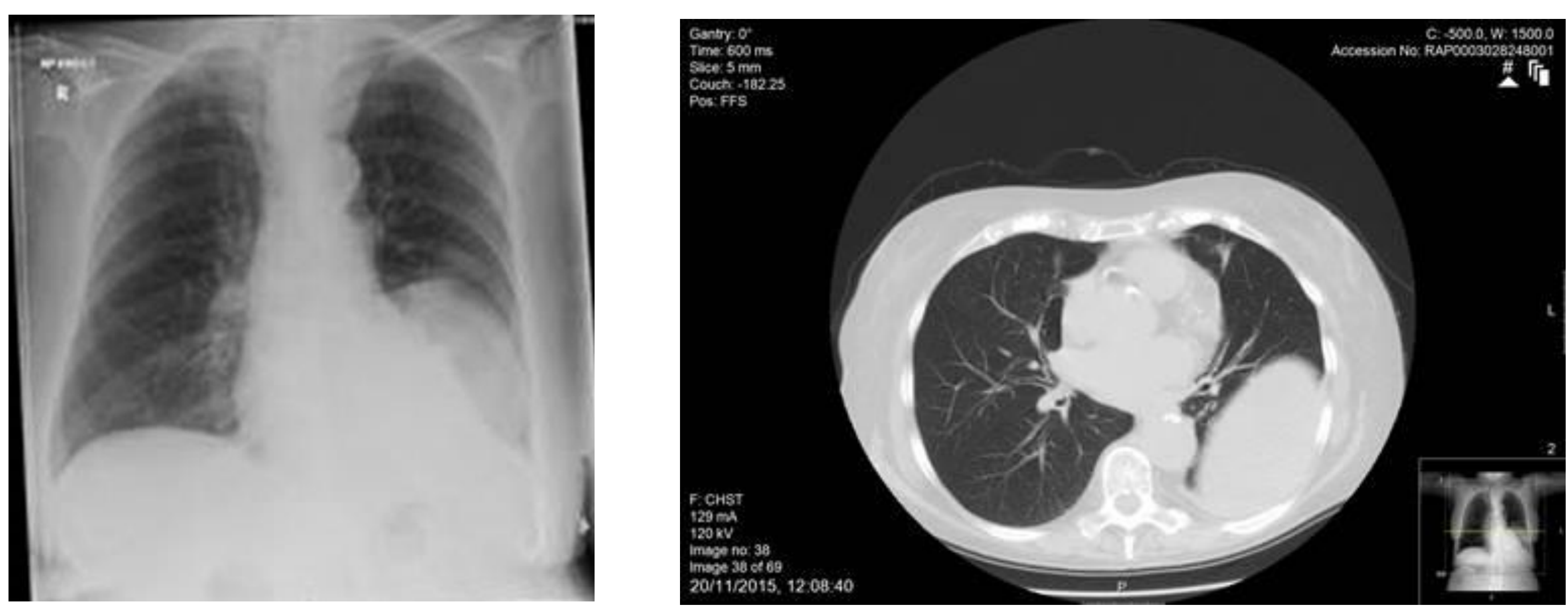

There is a large mass in the left lower zone, measuring $14 \times 12 \times 9 \mathrm{~cm}$. Mildly heterogenous in appearance with well defined margins. The lesion appears pleural or pulmonary in origin, but pleural is thought more likely. No mediastinal adenopathy on this non-contrast scan.

\section{MANAGEMENT}

She was commenced empirically on Predisnolone, and the dose titrated down to the lowest effective dose. At $10 \mathrm{mg} /$ day she remained free of hypoglycaemia. Given her disabling symptoms, and corticosteroid adverse effects a multidisciplinary decision was taken to proceed with surgical resection. She underwent a complete resection and made a good recovery functionally (post-op imaging to the right, significant atelectasis but complete tumour resection). Histology confirmed benign spindle cell lung fibroma. Repeat IGF2 measurement confirmed secretion had ceased. She has been free of hypoglycaemia since surgery and has been successfully weaned from corticosteroid therapy.

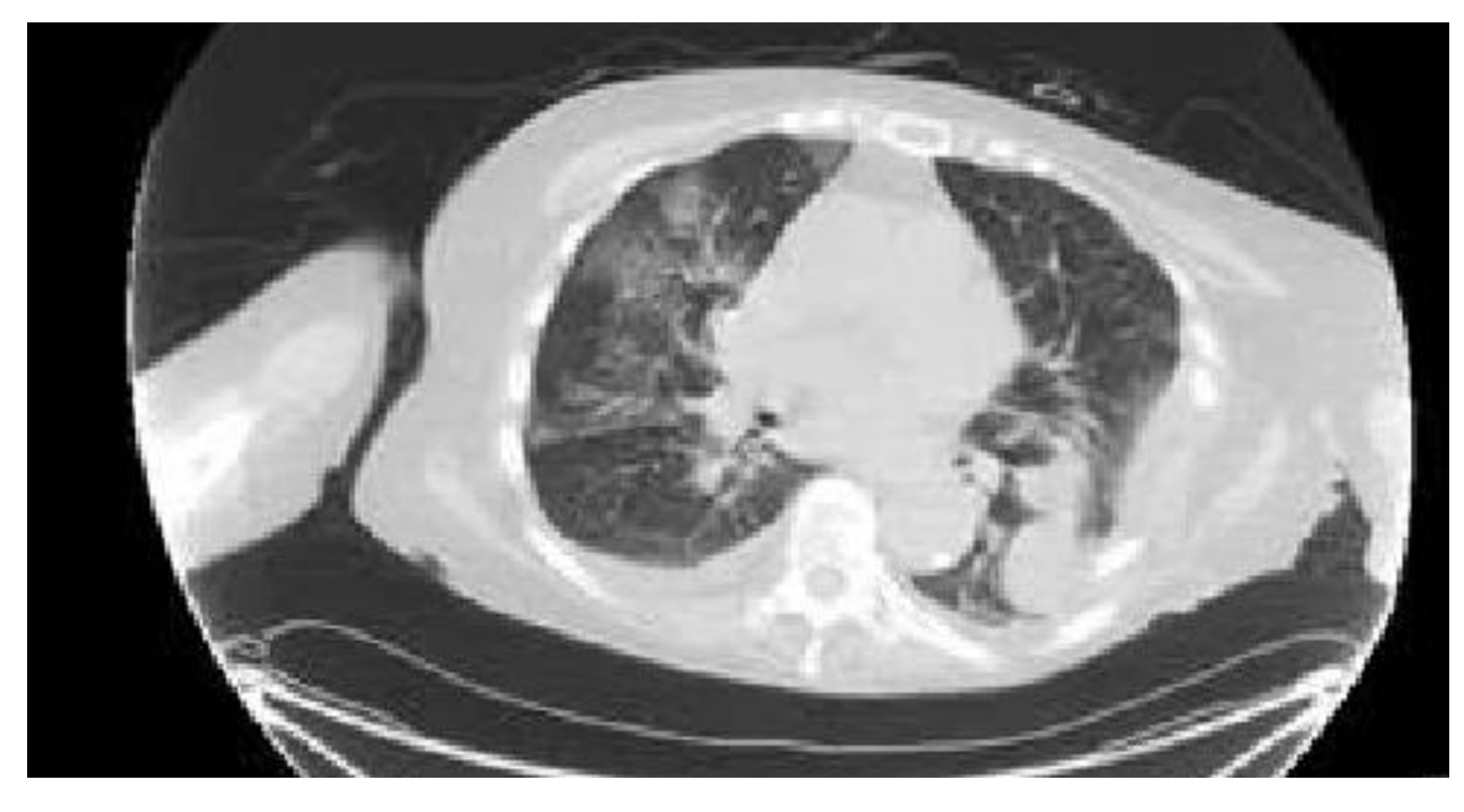

\section{DISCUSSION}

Non-islet cell tumour hypoglycaemia is a rare entity, which has been reported in other patients with pleural fibromas. It has been most commonly reported in association with tumours of mesenchymal or epithelial origin, but has been reported in many varieties of solid tumour. These tumours are usually large and readily detectable with conventional imaging. Glucocorticoids are the most effective medical therapy although diazoxide, somatostatin anologues and growth hormone therapy have all been found to have an effect. Surgery, where possible is curative however.

\section{REFERENCES}

Cryer et al, Evaluation and management of adult hypoglycemic disorders: an Endocrine Society Clinical Practice Guideline, J Clin Endocrinol Metab. 2009 Mar;94(3):709-28. doi: 10.1210/jc.2008-1410. Epub 2008 Dec 16. De Groot et al, Non-islet cell tumour-induced hypoglycaemia: a review of the literature including two new cases, Endocr Relat Cancer. 2007 Dec;14(4):979-93.

Hood et al, A case of spontaneous hypoglycaemia and impaired glucose tolerance in the same patient. Ann Clin Biochem. 2011 Mar;48(Pt 2):183-5. doi: 10.1258/acb.2010.010064. Epub 2011 Feb 21. 